\title{
Evaluation of Rosette Inhibition Test in Renal Transplantation
}

\author{
R. F. M. WOOD, AILEEN C. GRAY
}

British Medical fournal, 1973, 4, 649-651

\section{Summary}

Serial rosette inhibition tests were performed on 11 renal transplant patients in an attempt to predict graft rejection. The rosette inhibition titre was higher in immunosuppressed patients than in normal subjects. The test was of predictive value in only two out of 12 rejection episodes, where a fall in titre to normal levels occurred 48 hours and 24 hours, respectively, before biochemical evidence of rejection. In two further rejection episodes the titre fell at the time of rejection. The titre changes in all tests were small and there were frequent inconsistencies in the results of individual tests. A study of the variables was undertaken, with standardization of the technique, and improvements were made in reading the test. Despite these changes the test was still not sufficiently accurate or reliable to be used as the basis of treatment of rejection episodes.

\section{Introduction}

The rosette inhibition test was originally described by Bach and Antoine (1968) as an in-vitro method of assessing the activity of antilymphocyte globulin (A.L.G.). The test depends on the spontaneous formation of rosettes of sheep red blood cells around human lymphocytes in vitro. The addition of A.L.G. to this system inhibits rosette formation. By using a range of doubling dilutions of A.L.G. and counting rosettes per 1,000 lymphocytes at each dilution a rosette inhibition curve can be drawn (fig. 1). The rosette inhibition titre is taken at the point on the curve where there is a $25 \%$ reduction in numbers of rosettes compared with a control sample with no A.L.G.

Munro et al. (1971) described the use of the test in predicting acute rejection episodes in renal transplant patients. It was shown that in immunosuppressed patients and in patients with impaired immune status such as those with chronic renal failure, there was a shift of the rosette inhibition curve to the right with a consequent rise in titre. It was also shown that before biochemical evidence of a rejection episode the curve shifted back to the left with a fall in the rosette inhibition titre to normal levels (fig. 2). We have used the test in 14 normal subjects, eight dialysis patients, and 11 renal transplant patients in an attempt to confirm these findings.

\section{Materials and Methods}

The technique used was basically that originally described by Bach and Antoine (1968) and Bach et al. (1968). Lymphocytes were obtained from $10 \mathrm{ml}$ samples of heparinized peripheral blood ( $25 \mathrm{IU}$ of preservative-free heparin $/ \mathrm{ml}$ ) by spinning

\footnotetext{
University Departments of Surgery and Pathology, Western Infirmary, Glasgow G11 6NT

R. F. M. WOOD, M.B., F.R.C.S., Surgical Registrar

AILEEN C. GRAY, B.SC., Research Assistant
}

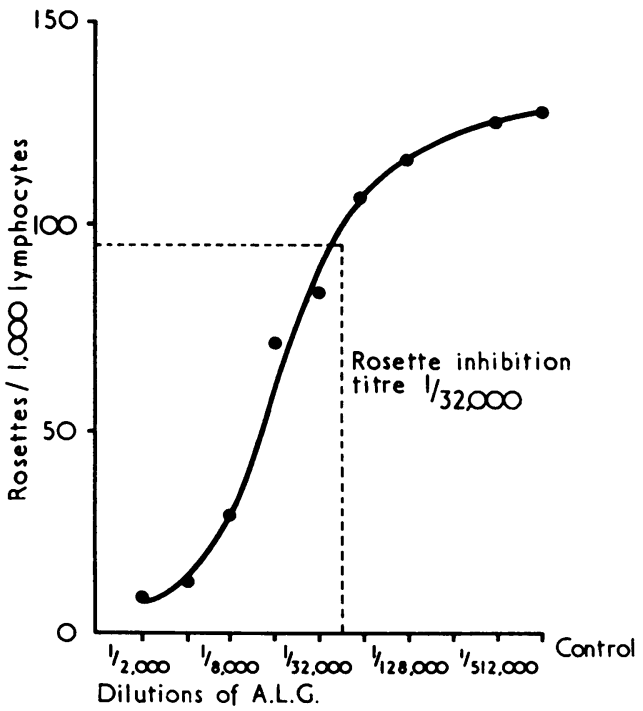

FIG. 1-Normal rosette inhibition test. A.L.G.= Antilymphocyte globulin.

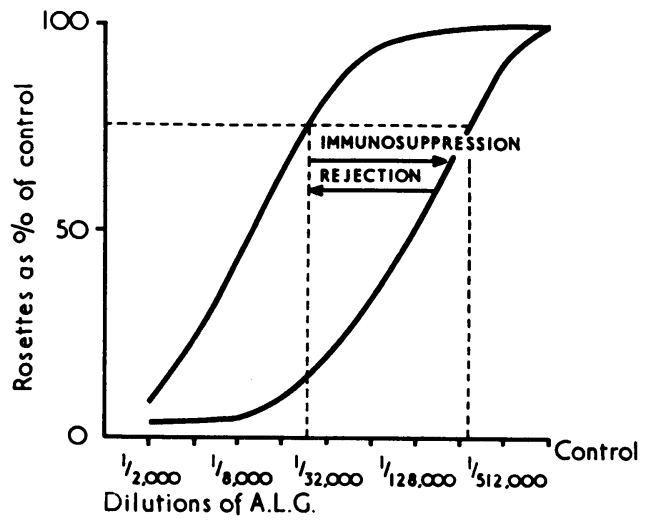

FIG. 2-Alterations in rosette inhibition titre with immunosuppression and rejection.

over a Ficoll-Hypaque gradient (Harris and Ukaejiofo, 1970). The lymphocyte suspension was made up to a concentration of $5 \times 10^{6}$ cells $/ \mathrm{ml}$ in Hank's balanced salt solution. A $0.1 \mathrm{ml}$ sample of this suspension was then added to $0.2 \mathrm{ml}$ serial dilutions of A.L.G. in Hank's solution in disposable plastic tubes. Finally $50 \mu \mathrm{l}$ of a $1 / 5$ dilution of fresh guinea-pig complement and $50 \mu \mathrm{l}$ of fetal calf serum were added to each dilution tube. The tubes were then incubated for 90 minutes at $37^{\circ} \mathrm{C}$. A red cell suspension was prepared from fresh sheep red cells which had been washed and packed (10 $\mu$ l of sheep cells in $6.5 \mathrm{ml}$ Hank's solution). A $0.1 \mathrm{ml}$ sample of this red cell suspension was added to each dilution tube and the tubes were spun down at $70 \mathrm{~g}$ for five minutes. The tubes were then placed on a rotating disc at 10 r.p.m. to resuspend the cells 
and rosettes. The preparations were counted in FuchsRosenthal counting chambers.

Eleven patients were studied serially during the first three months after renal transplantation. All were receiving oral prednisolone and azathioprine as immunosuppressive therapy. Rejection was diagnosed if either a reduction in urine volume and creatinine clearance or a rise in serum creatinine persisted for more than 24 hours. Additional clinical evidence of rejection such as pyrexia, graft swelling, and tenderness was sometimes seen.

\section{Results}

An initial study showed that the rosette inhibition titre was raised both in transplant patients with stable renal funotion and in the dialysis patients when compared with the values in the normal subjects. The rosette inhibition titre in normals was $1 / 16,000$ or $1 / 32,000$; in dialysis patients the average titre was $1 / 128,000$, with levels of up to $1 / 512,000$ in transplant recipients. The 11 renal transplant patients were then tested regularly during the first three months after operation in an attempt to predict rejection episodes. There were 12 rejection episodes which satisfied our biochemical criteria. In only two of the 12 episodes was the test of predictive value, with a fall in titre occurring 48 hours and 24 hours, respectively, before the biochemical changes of rejection. In two funther rejection episodes the titre fell at the time of rejection. The clinical details and serial titres in one of these latter patients are shown in fig. 3 . Before and during the other eight rejection episodes the titre remained unchanged. There were eight false positive results in six patients, with a fall in titre in the absence of clinical or biochemical evidence of rejection. No correlation between the test results and the doses of immunosuppressive drugs was found.

Results of several individual tests were unsatisfactory and there was often difficulty in interpreting the exact level of the rosette inhibition titre. On several occasions we found that the confidence limits of the curve spanned two dilutions of A.L.G. (fig. 4). In the patients on immunosuppressive drugs the titre was usually $1 / 128,000$ or $1 / 256,000$ with an average of $2 \cdot 2$ dilutions of difference from normal levels. With this small titre difference we felt that the accuracy of the test would have to be beyond doubt if the results of one individual estimation were to be used as the basis of treatment of rejection with large doses of steroids or A.L.G.

To try to ensure the accuracy of our results we undertook an assessment of the variables in the test.

The technique was standardized and we took precautions such as ensuring that the resuspension time was exactly five minutes and removing samples from the surface of the dilution tubes immediately after resuspending.

A series of paired tests were performed with and without fetal calf serum. There were no significant differences in the results and it was therefore omitted from subsequent tests.

Bach et al. (1969) stressed the importance of using freshlyprepared guinea-pig complement in the test. However, we found that if the complement was stored at $-70^{\circ} \mathrm{C}$ in small aliquots activity was retained for up to a month. After that there was a drop in activity with less inhibition of rosette formation at each dilution of A.L.G.

We found that for satisfactory results fresh sheep red cells were required every week; cells stored in Alsever's solution were not suitable for use in the test.

The A.L.G. we used for routine testing was a thymusderived horse anti-human preparation (Burroughs Wellcome Research Laboratories). Ampoules were handled in a standard fashion. Sterile precautions were taken in opening the ampoule and the contents were diluted $1 / 20$ in Hank's balanced salt solution. Diluted A.L.G. was dividied into small aliquots in sterile bottles and stored at $-20^{\circ} \mathrm{C}$. A fresh aliquot was used for each day's test and diluted A.L.G. was discarded after a month.

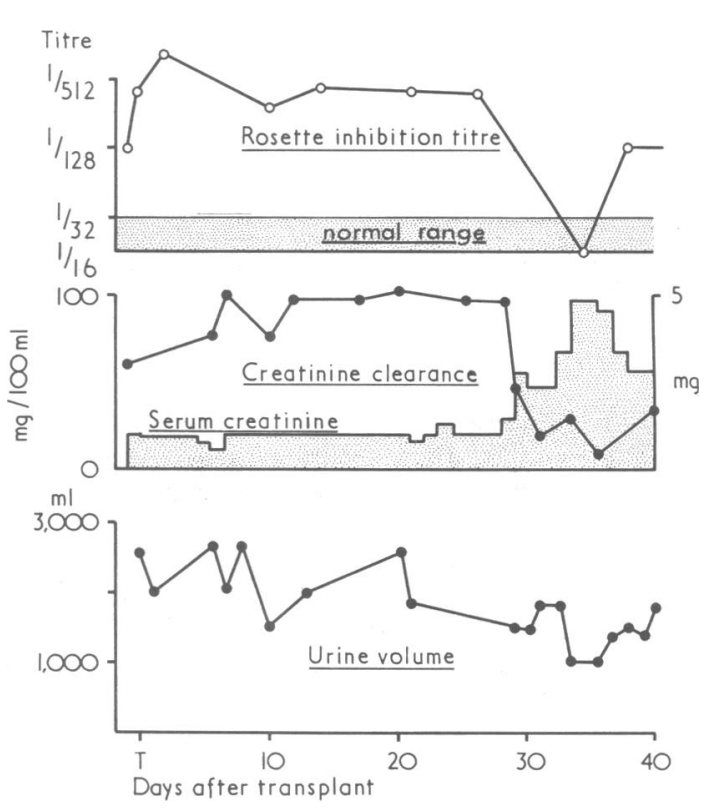

FIG. 3-Clinical details and rosette inhibition titres in a patient with a rejection episode starting 28 days after transplantation.

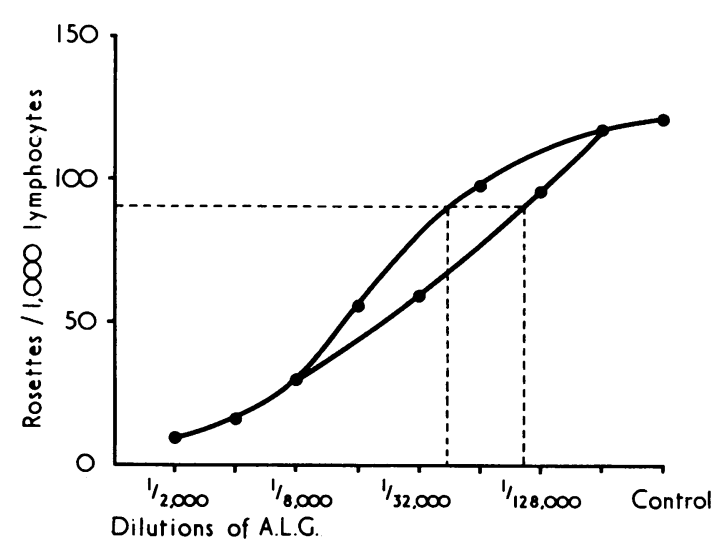

FIG. 4-Rosette inhibition curve showing difficulty in interpretation of titre level when confidence limits span two dilutions of A.L.G.

Previous reports have suggested that there is a loss of the immunosuppressive potency of A.L.G. with storage (Judd and Trentin, 1971; Shanfield et al., 1971). Our unopened ampoules of A.L.G. were initially kept at $4^{\circ} \mathrm{C}$, and under these conditions the level of the rosette inhibition titre in normal subjects fell from the usual $1 / 32,000$ to levels around $1 / 8,000$ after a year's storage. However, activity is fully retained if the ampoules are stored at $-20^{\circ} \mathrm{C}$.

In practice, observer error is one of the greatest problems in the test. In an unstained preparation rosettes are fairly readily seen but lymphocytes are often difficult to identify with certainty. A series of 20 paired tests were performed to estimate reliability and observer error. In only $14(70 \%)$ of the paired tests was the same rosette inhibition titre achieved. In four of the tests there was one dilution difference in titre and in two of the tests two dilutions of difference. The total observer error was $15 \%$, with a lymphocyte counting error of $20 \%$ and a rosette counting error of $8 \%$. The tests were counted by four observers who all had wide experience with the test. 
Staining of the unfixed preparation did not improve our results. Unfortunately both methylene blue and toluidine blue inhibit rosette formation when used in sufficient concentration to stain the lymphocytes. Trypan blue is unsatisfactory because most of the lymphocytes remain viable. Eosin staining of the red cells is equally unsatisfactory because the prominent pink background still makes it difficult to identify the lymphocytes. We found three ways of reducing observer error to acceptable levels. Firstly, by counting rosettes in the noraml way and then taking a separate sample from each dilution tube and performing a normal white count with diluting fluid. Phase contrast microscopy is also effective in reducing observer error. Undoubtedly the most accurate method is to fix the preparation with glutaraldehyde and then stain the lymphocytes with trypan blue (Haskill et al., 1972). However, the technique is timeconsuming and not really suitable for daily testing with a range of A.L.G. dilutions.

\section{Discussion}

The prediction and even the diagnosis of renal transplant rejection still present problems despite the introduction of a variety of tests. On a theoretical basis, tests detecting changes in the lvmphocyte population would appear to offer the best chance of predicting impending rejection at the earliest stage. The value of the leucocyte migration test in predicting rejection has already been established (Smith et al.. 1969: Weeke et al. 1970; Falk et al., 1972; Galanaud et al., 1972; House et al., 1973; Wood et al., 1973). An increased spontaneous uptake of radioactive-labelled thvmidine in "activation lvmphocvtes" (Hersh et al., 1971) and an increase in lvmphoblast transformation in response to phytohaemagglutinin (Rubin et al.. 1964; House et al., 1973) have both been shown to precede biochemical evidence of rejection. The rosette inhibition test was shown by Munro et al. (1971) to be of predictive value in the detection of rejection, and Bewick et al. (1972) described the use of the test in monitoring the level of immunosuppressive therapy. The advantage of the rosette inhibition test over these other techniques is the speed with which a result can be obtained. It is possible to complete the test within four hours and this gives the prospect of a rapid confirmatory test in a patient who is thought to be rejecting on clinical or biochemical grounds. It was for this reason that we studied the test in postoperative renal transplant patients. Our recults have failed to confirm those of Munro et al. (1971). In only two out of 12 rejection episodes was the test of predictive value, though in a further two rejection episodes titre levels fell at the time of rejection. There were a number of false positive results, and despite a study of the variables involved we were unable to improve significantly on the accuracy or reliability of the test.

The fact that there are changes in rosette inhibition titres with immunosuppressive therapy is notewonthy but at the present time the use of the test in the prediction of rejection is empirical. The phenomenon of spontaneous rosette formation of sheep red cells around human peripheral blood lvmphocvtes is still poorly understood. In mice spontaneous rosette formalion has been shown to be an effective T-cell marker (Raff, 1971). In man, however, Chapel (1973) has shown that with repeated washing with phosphate-buffered saline $73 \%$ of peripheral blood lvmphocytes will form rosettes. This number can be increased to $28 \%$ with papain treatment. It seems likely therefore that in normal circumstances both $\mathrm{B}$ - and $\mathrm{T}$-cells are invo'ved in spontaneous rosette formation. There is no experimental evidence to explain the titre shifts in the rosette inhibition test in immunosuppressed patients compared with normal subjects. There is obviously an alteration in the lvmphocyte population. and the change of titre is probably due to a relative reduction in $\mathrm{T}$-cells and also to a metabolic effect of the immunosuppressive drugs on the lymphocytes; the metabolic effect rendering the cells less able to bind sheep red cells and more readily coated by the A.L.G. In the immediate postoperative period we have noted an appreciable reduction in the numbers of spontaneous rosette-forming cells, in the control situation with no A.L.G., with rosette numbers then tending to rise within the first week after operation to levels around $75 \%$ of the preoperative value. This would suggest either that the effects on the lymphocyte population of the large initial doses of immunosuppressive drugs are as much metabolic as cytotoxic or that they produce a change in the proportions of immature and mature T-cells.

A fall in titre with rejection could be explained by the appearance of a population of immunocompetent $T$-cells directed against the graft. If the numbers of spontaneous rosette-forming cells in the control tubes reflected the level of T-cells in the peripheral blood then one might hope to predict rejection by a rise in the numbers of these cells. A review of all our results has failed to show any convincing evidence to suppont this. There was a fairly wide daily fluctuation in numbers of spontaneous rosette-forming cells of from 10 to $40 \%$ in control subjects. Technical considerations are probably the most important factor in this variation; different authors have found levels of spontaneous rosette-forming cells from 0.4 to $2.6 \%$ (Bach et al., 1969) up to 50 to $73 \%$ (Chapel, 1973) depending on experimental conditions.

In conclusion, a test which is to be used as the basis of the treatment of rejection should be both accurate and reproducible. Unfortunately, in its present form the rosette inhibition test satisfies neither of these criteria. A larger titre difference with immunosuppression and rejection would certainly improve the value of the test. We have tested a variety of A.L.G. preparations to look for bigger titre differences but none were distinctly superior to the Burroughs Wellcome A.L.G. in this respect. It would possibly be of benefit to have a freeze-dried A.L.G. preparation and test this against a bank of frozen reference cells to standardize the test.

We would like to thank Professor J. R. Anderson, Professor P. R. F. Bell, and Dr. J. D. Briggs for their continued support and interest in this work.

We would also like to thank Dr. A. W. Phillips and Mrs. B. Mosedale, of Wellcome Research Laboratories, for their help and their generosity in supplying antilymphocyte globulin.

The research has been supported by a grant from the Higher Medicine Funds of the Western Regional Hospital Board.

\section{References}

Bach, J. F., and Antoine, B. (1968). Nature, 217, 658.
Bach, J. F., Dardenne, M., and Antoine, B. (1968). Pathologie et Biologie, 16,657 .

Bach, J. F., Dormont, J., Dardenne, M., and Balner, H. (1969). Transplantation, 8, 265.

Bewick, M., Ogg, C. S., Parsons, V., Snowdon, S. A., and Manuel, I. (1972). British Medical fournal, 3,491.

Chapel, H. M. (1973). Transplantation, 15, 320.

Falk, R. E., Guttmann, R. D., Beaudoin, J. G., Morehouse, D. D., and Oh, I. H. (1972). Transplantation, 13, 461. Galanaud, P., Crevon, M. C., Dormont, J., Mahieu, P., and Weydert, A.

Harris, R., and Ukaejiofo, E. O. (1970). British fournal of Haematology, 18, 229.

Haskill, I. S., Elliott, B. E., Kerbel, R., Axelrad, M. A., and Eidinger, D. (1972). Fournal of Experimental Medicine, 135, 1410

Hersh, E. M., Butler, W. T., Rossen, R. D., Morgan, R. O., and Suki, W. (1971). Fournal of Immunology, 107, 571

House, A. K., Boak, J. L., and Carolin, D. (1973). Transplantation, 15, 359. Judd, K. P., and Trentin, T. I. (1971). Transplantation, 12, 83.

Munro, A., et al. (1971). British Medical fournal, 3, 271

Raff, M. C. (1971). Transplantation Reviews, 6, 52.

Rubin, A. L., Stenzel, K. H., Hirschhorn, K., and Bach, F. (1964). Science, 143,815 .

Shanfield, I., Wren, S. F. G., and MacLean, L. D. (1971). Transplantation 12,80 .

Smith, M. G. M., et al. (1969). British Medical fournal, 4, 275.

Weeke, E., Weeke, B., and Bendixen, G. (1970). Acta Medica Scandinavica, $188,307$.

Wood, R. F. M., Gray, A. C., Briggs, J. D., and Bell, P. R. F. (1973). Transplantation, 16, 41 . 